\title{
Deus se revela mesmo em tempos difíceis
}

Celso Pinto Carias ${ }^{1}$

\section{Introdução}

Em dezembro de 2019, o noticiário começou a falar de um vírus que estava matando na China. Rapidamente o mesmo noticiário começou a falar de uma pandemia causada por uma variante de um vírus já conhecido, mas que passou a ser chamado de novo coronavírus. $\mathrm{A}$ doença causada pelo vírus passou a ser chamada de COVID-19. Estamos com quase dois anos de pandemia e o número de mortes tem sido alarmante. Como o vírus não escolhe as suas vítimas, embora mate mais idosos, temos notícia, ou até conhecimento direto, de famílias inteiras ceifadas por consequências do contágio. Neste contexto, uma pergunta tão antiga quanto a presença das religiões na história da humanidade reapresenta-se com força: onde está Deus nisso tudo?

Seria muita ousadia de nossa parte querer oferecer resposta a uma pergunta tão profunda, ainda mais em um espaço tão curto como o que ora se apresenta. No entanto, vamos refletir duas realidades que são fundamentais para buscar um caminho de resposta. Trata-se, primeiramente, de se perguntar quanto à origem do mal e a partir daí buscar os sinais da presença de Deus. Também não temos condições de ampliar o quadro reflexivo em relação ao conjunto do pensamento religioso planetário, por isso vamos nos restringir, brevemente, à tradição cristã.

\section{0 mal não vem de Deus}

Onde se encontra o ser humano criado à imagem e semelhança de Deus? Qualquer pessoa que tenha alguma aproximação da fé judaico-cristã deve, no mínimo, fazer algum tipo de questão em torno deste elemento que compõe uma verdade para esta tradição. Na reflexão sobre a valorização do ser humano na obra da criação pode parecer que depositamos um otimismo exagerado na pessoa humana. Até mesmo podemos pensar em certo esquecimento da complexidade e ambiguidade do mundo, no qual a dor, o sofrimento, a injustiça, o mal e o pecado possuem grande influência. Não percamos de vista a questão central: como devemos encarar os limites humanos no contexto de uma criação boa de Deus?

A angústia diante do sofrimento e da realidade do mal no mundo, sobretudo quando não se encontra alguma justificativa para explicar o sofrimento de alguém (por exemplo: "está pagando pelo mal que fez"), tem acompanhado o ser humano desde tempos mais distantes. $\mathrm{Na}$ Bíblia, o livro do Gênesis possui 11 capítulos sobre este tema. Também na Sagrada Escritura, o

\footnotetext{
${ }^{1}$ Doutor em Teologia pela PUC-Rio. Professor do Setor de Cultura Religiosa do departamento de Teologia da PUCRio. Assessor da Ampliada Nacional das CEBs e do Setor Cebs da Comissão Pastoral Episcopal para o Laicato da CNBB. Da equipe do Iser Assessoria e morador de Duque de Caxias, RJ - Baixada Fluminense.
} 
tema é recorrente, e se torna central, por exemplo, no livro de Jó. Em toda a história da Igreja encontraremos alguém preocupado com esta questão: Santo Agostinho, por exemplo, formulou a doutrina do pecado original tendo esta preocupação de fundo.

No entanto, no cristianismo, a grande revelação sobre como devemos encarar a dor, o sofrimento e o mal, se encontra na cruz de Jesus Cristo. Neste artigo não teremos condições de aprofundar este tema da fé cristã, mas desejamos indicar que, na própria constituição humana, existem elementos para enfrentar tal desafio.

O ser humano é limitado, mesmo tendo aspirações ilimitadas. Nós não nos conformamos em apenas sobreviver. Queremos sempre mais. Nunca estamos satisfeitos. É bom lembrar que não somos deuses. É importante nos darmos conta de que imagem e semelhança não é sinônimo de igualdade. A busca da igualdade com Deus é o pecado dos pecados, como narra o Gênesis, com toda a sua carga simbólica, naturalmente: querer dominar, comendo o fruto proibido da árvore do conhecimento do bem e do mal, foi o pecado que marcou e continua marcando toda humanidade. Entendemos por pecado tudo o que desumaniza. Precisamos ter cuidado com versões moralizantes quanto a isso. A carga de desumanização presente no contexto de pecado em que estamos inseridos não nos deixa perceber que a questão fundamental da existência humana não é o sofrimento, e sim quais pensarmos quanto às condições humanas para enfrentá-lo.

Com os olhos fechados pelo pecado da arrogância, o mal vai se fortalecendo. Na ânsia de, utilizando o poder da inteligência, querer ocupar o lugar de Deus, o ser humano vai alargando as consequências do mal e, com isso, criando um processo de desenvolvimento de vários sinais de desumanização. O que foi equivocadamente identificado como um "pé de maçã" no relato do Gênesis, consiste na metáfora da árvore do conhecimento do bem e do mal. Essa é a fruta que, quando cedemos ao desejo de controle, passamos a criar uma rede de distribuição do mal, na procura de estarmos acima de tudo e de todos. Ao lermos a narrativa do Gênesis, vemos que o ser humano dá início a um processo de afastamento de todo o bem, de desencontros com toda a Criação, de abandono da relação amorosa com Deus. O mal não é sofrer. O mal não é ver uma criança sofrendo. O mal é não sermos capazes de nos ajudar diante da dor e do sofrimento. É não sermos capazes de reconhecer que o caminho humano é a busca constante de superação de si mesmo, pois isto nos capacita para o encontro definitivo com Deus. Como animais, do ponto de vista biológico, somos constituídos por uma limitação estrutural e, portanto, passíveis de dor.

Ninguém tem uma resposta definitiva em face da dor e do sofrimento. Porém, podemos ter certeza de uma coisa: Deus não é um carrasco, ou sádico, que nos quer ver sofrer, nem mesmo para 'aprendermos' alguma coisa. No entanto, se somos feitos à sua imagem e semelhança, certamente deve existir algo no sofrimento que esteja próximo da própria realidade de Deus. E, pela criação livre de Deus, somos convidados a reconhecer, em nós mesmos, a capacidade de ir ao seu encontro, mesmo no meio da dor. Não façamos da dificuldade de compreendermos esta realidade humana um pretexto para causar ainda mais sofrimento, 
chegando até a introduzirmos processos que causam o mal, supostamente para aliviar o sofrimento. O sofrimento é parte da condição humana, mas são necessários discernimentos científicos, comunitários e pessoais, para que as escolhas não se desdobrem em autodestruição pessoal, coletiva e do mundo criado.

Temos assistido, durante a pandemia, justamente a banalização do mal ou a justificação do mal como realidade divina. Diante disso podemos nos perguntar: como reconhecer que Deus se revelou e se revela diante de tal realidade. Como podemos compreender que Ele está no meio de nós diante de uma realidade, muitas vezes, brutal e injusta?

\section{Revelação de Deus na história humana}

Compreendendo a realidade do ser humano criado por Deus em um contexto em que o mal é uma possibilidade concreta, passaremos a refletir sobre como este mesmo Deus se revela na obra da criação ao homem e à mulher criados à sua imagem e semelhança. É preciso verificar como se dá a iniciativa divina de não abandonar a humanidade em sua fragilidade. Não é uma tarefa fácil, pois os conceitos, os termos, as palavras que serviram de base para a formulação da teologia que dá suporte à fé cristã, foram estruturados em uma linguagem muito distante de nosso ambiente cultural atual.

Queremos lançar um pequeno facho de luz para a compreensão do processo no qual o ser humano percebe a manifestação de Deus em sua história. Assumiremos aqui o caminho do teólogo holandês E. Schillebeeckx, em sua obra "História humana, revelação de Deus". O referido teólogo faz uma proposta metodológica que muito nos ajuda na compreensão do conceito de revelação diante do paradigma cultural atual. Para este teólogo, com quem concordamos, havia uma perspectiva que, para perceber a realidade divina seria necessário implantar em todos os recantos do mundo a fé crista. Ele nos convida, então, a mudar o foco. Havia uma concepção antiga que afirmava: "Fora da Igreja não há salvação", tornando muito difícil perceber que Deus está em todo universo criado. Diante dessa concepção, ele propõe a seguinte: "Fora do mundo não há salvação", a fim de proporcionar uma reflexão mais coerente com o próprio texto do Novo Testamento e, ao mesmo tempo, com a realidade da história humana moderna. Vamos colocar algumas pistas para tentar entender a seguinte questão: o que é revelação de Deus? E para não ficar com uma compreensão mágica da revelação de Deus, buscaremos esclarecer algumas coisas.

Estamos acostumados a pensar, por causa de uma leitura fundamentalista dos textos bíblicos, isto é, ao "pé da letra", que a revelação de Deus acontece de forma direta, sem mediação. Por exemplo, Deus escolheria uma pessoa ou povo para quem comunicaria, diretamente - como que utilizando um "telefone divino" -, a sua vontade. Na Bíblia, por exemplo, Deus teria ditado no ouvido dos redatores o que deveria ser escrito, sem nenhuma intervenção da cultura humana. Ora, Deus não criou bonecos para brincar, criou seres humanos com liberdade, com capacidade de decidir, como já fizemos menção. O fato de ser à sua imagem e 
semelhança, não significa que podemos prescindir de nossa estrutura humana para compreender o Criador e sua vontade para nós.

É preciso levar em consideração que quando nos referimos a Deus usamos linguagem humana e não divina. Alguém conhece o idioma de Deus? Teria Deus privilegiado uma cultura para expressar sua vontade? Todas as nossas imagens de Deus são imperfeitas, são aproximações da realidade de Deus e não Deus em sua plenitude. Quando assumimos, por exemplo, que Deus é Pai, como o próprio Cristo nos mostrou, deve-se ter em mente que Ele não é pai como nós somos pais. Até mesmo uma das melhores definições de Deus, que encontramos em 1Jo 4,16 (Deus é amor) não esgota tudo o que seja Deus, pois o amor de Deus não é como o nosso amor. Embora todas essas expressões contenham uma verdade sobre Deus, essas expressões não podem ser confundidas com Deus em si mesmo, pois o nosso saber é estruturado pela capacidade humana de organizar o pensamento e não pelo modo do ser divino.

Vamos dar um exemplo para entender melhor o que acabamos de afirmar. Quando nos referimos a Luiz Alves de Lima e Silva (o Duque de Caxias, herói brasileiro que dá nome à cidade onde vivo), referimo-nos a alguém real, mas que foi apresentado na história com conceitos e informações disponíveis aos narradores. Ora, nem sempre os mesmos conseguiram ser fiéis na apresentação daquele Luiz que viveu no Brasil no século XIX. Hoje sabemos que durante a guerra do Paraguai, o famoso "Pacificador" foi responsável por verdadeiras chacinas. Assim, em torno da imagem de um "herói", existem fatos reais e fatos projetados, de acordo com os interesses de quem quer passar a mensagem. Se os interesses forem humanizantes, o bem poderá ser construído, mas podem carregar uma ambiguidade que gere atitudes desumanas, e aí o mal encontra um caminho fecundo.

O que foi dito acima serve para percebermos a dificuldade de expressar exatamente aquilo que seja Deus e sua vontade, pois não deixamos de ser humanos quando tentamos compreender a direção que Deus tem para nós. Tudo o que somos, e como somos, entra na compreensão de Deus. Então, para dizer quem é Deus e como Ele se revela, é preciso assumir a história humana, é preciso valorizar o mundo, e não fugir do mundo. É no mundo, na natureza, em todo cosmo, que encontramos os vestígios do Criador.

Assim, o que identificamos como revelação de Deus é percebido no interior do conjunto de nossas experiências mais profundas como ser humano, que constata o caminho que Ele "pensou" para a criação. Essas experiências são narradas pela linguagem religiosa e, no nosso caso, pela tradição cristã que se deu, por excelência, em Cristo Jesus. Contudo, é preciso afirmar que essas mesmas experiências só são possíveis porque Deus mesmo toma a iniciativa de se revelar, porque Ele quer que nós compreendamos e sigamos o caminho da salvação. Porém, não somos deuses, por isso, como alguém que caminha com os olhos fechados, precisamos tomar cuidado para não tropeçar, e acabar por identificar Deus onde Ele não está. Esta é a essência do que se chama, biblicamente, de idolatria: colocar algo ou alguém que não seja Deus em seu lugar. $E$ isto pode acontecer mesmo no interior da linguagem religiosa. Pessoas podem 
estar pregando Deus mas, no fundo, apontarem para uma experiência idolátrica como, para exemplificar, confundir Deus com o ter, o poder ou o sucesso. Esta compreensão básica de revelação é fundamental para a nossa resposta a essa mesma revelação: a fé. É condição para experimentarmos com profundidade o desejo salvífico que Deus tem para todo ser humano. E se analisarmos bem o que está acontecendo na realidade atual, e não somente no Brasil, podemos justamente verificar o quanto o "nome" de Deus vem sendo utilizado de forma indevida.

Agora, na pandemia, apesar de todas as contradições, podemos olhar para realidade e perceber que a responsabilidade por tal situação não é de Deus, e sim das contradições humanas. Por outro lado, podemos perceber como Deus continua a suscitar pessoas que defendem a humanidade e nela a natureza e o cosmo, necessários para que haja vida para todos e todas. Podemos perceber que a escolha de Deus é por um caminho de paz, fraternidade, solidariedade, e não de violência. Todas as vezes que se experimenta tal realidade se pode experimentar um pouco do próprio Deus. Na dinâmica da fé cristã, o Deus que cria e se revela em Jesus Cristo, caminha com o ser humano na história para superar ambiguidades e fazer deste mundo um espaço de harmonia com aquilo que será conhecido na eternidade.

\section{Questões para reflexão:}

1. Como você encara a realidade do mal em sua vida?

2. Diante da reflexão apresentada no texto é possível perceber que o mal não tem origem em Deus?

3. Como relacionar a presença de um Deus que é Amor com a realidade em que vivemos hoje, onde muita coisa é justificada a partir de uma determinada visão de Deus?

\section{BIBLIOGRAFIA}

CARIAS, Celso Pinto. Teologia para todos. Manual de Iniciação Teológica a partir dos seus principais temas. 3 ed. Petrópolis: Vozes, 2006.

GONÇALVEZ, Alonso. Revelação e Decolonialidade. Subversão Teológica e Epistemologia Decolonial. São Paulo: Editora Recriar, 2021.

SCHILLEBEECKX, Edward. História Humana: Revelação de Deus. São Paulo: Paulus, 1994.

SOLLE, Dorothee. Sofrimento. Petrópolis: Vozes, 1996. 